\title{
Liderazgo en el \\ Comportamiento Organizacional
}

Lourdes Tamés Pidal*

dinstitucion@lasallep.edu.mx

Salvador F. Loya Loya

Trillas, 2006

El libro Liderazgo en el Comportamiento Organizacional de Salvador F. Loya Loya nos presenta en una forma general, con una visión holística, los factores que influyen y modifican los sistemas de liderazgo en las organizaciones (empresas, instituciones, dependencias).

Aun cuando no tenemos referencias sobre otras publicaciones del mismo autor, se descubre en este libro un conocimiento profundo sobre los temas relacionados con los sistemas de liderazgo en las teorías y las prácticas modernas. Su experiencia como director de CRODE Chihuahua (Centro Regional de Optimización de Equipo del Sistema Nacional de Institutos tecnológicos) entre 1993 y 1996 se ve reflejada a lo largo de la obra. Es un libro que a la vez de sintetizar y mencionar la gran mayoría de los estudios sobre el tema, complementa dicho referente con sus propias teorías y modelos que proponen nuevas formas de abordar el liderazgo. Es un libro sobre administración, didáctico y a la vez sencillo de leer.

El autor se propone dar una idea general de las técnicas recomendadas para llegar a ser un líder, incluye además herramientas y conclusiones sobre su aplicación que resumen su experiencia. Busca ser un libro de introducción al tema para alumnos que no han estudiado el liderazgo y a la vez, servir de apoyo a personas que ejercen dicha posición en cualquier nivel.

El libro está estructurado en tres grandes apartados. Inicia de la introspección y valoración personal. Busca llevar al lector (interesado en ejercer el liderazgo) a descubrir los aspectos personales que afectan de manera sustantiva en la capacidad individual de liderazgo. Describe al hombre actual como un ente conformado por razón, emoción, cuerpo y espíritu. Menciona que cada vez es más sencillo sobresalir entre los demás porque aun cuando cada vez somos más humanos, prevalece la falta de voluntad y de sentido de las mayorías, que no utilizan sus tres cualidades esenciales: pensar, sentir y actuar. Como seres individuales podemos calificar la calidad de la actuación con base a la conjugación equilibrada entre sentimiento, razón, valores y creencias.

Describe los diferentes tipos de valores: trascendentes, relativos, sociales, morales, temporales, biológicos, estéticos, teóricos, políticos, económicos y menciona que, cada individuo establece una axiología propia con escalas individualizadas. Dice que las personas buscan trabajar en organizaciones que 
tienen valores similares a los propios o viceversa: la empresa, contrata a individuos con escalas de valores similares a los de la organización.

Para el individuo el tener debe ser una consecuencia del ser, saber y hacer. Sugiere que de esa forma lo que se pierda podrá recuperarse fácilmente. La madurez para Loya es más una actitud razonada que un proceso natural que se deriva de aprender de las emociones, no necesariamente controlándolas, sino reconociéndolas y decidiendo la actitud que debe tenerse. Sugiere utilizar le empatía y técnicas de disociación, es decir, salirse del problema, verlo desde otra perspectiva, como lo vería otra persona; antes de responder a un estímulo para así tomar una decisión madura. Al final de este capítulo propone un ejercicio para descubrir valores y creencias determinantes de nuestra conducta.

Aún en el primer apartado empieza a analizar elementos en los que interviene la relación individual con el exterior. Elementos como la percepción, la comunicación y la motivación van cerrando el análisis individual. Las características que individualizan al ser humano referenciado de Edmundo Velasco son las neurológicas, las culturales y las individuales. Después de describirlas sugiere técnicas de Programación Neurolinguística para favorecer los mecanismos de percepción, que es el proceso individual de registrar al mundo por medio de sensaciones y crear un mundo en la mente de una manera única, "nadie y todos, tienen la verdad" ( $p .38)$. Sobre la comunicación puntualiza que es algo generado en la mente de quien la propone, por lo que es una actividad del individuo que la genera. Si las ideas a comunicar no son claras, ningún medio podrá aclararlas. Describe sus elementos: idea, idioma, habla, comunicación no verbal, etc. "La comunicación tiene tres elementos: palabras, tono e inflexiones de voz y los gestos...." (p.44). Puntualiza que la comunicación no verbal se da a propósito y sin él. Sobre motivación analiza las teorías de Maslow y Herzberg. Propone herramientas de participación y reconocimiento para despertar la motivación en el individuo y en el grupo. Introduce ejercicios para clarificar los conceptos y dominar técnicas de percepción, comunicación y motivación.

El segundo apartado trata sobre los grupos. Se definen y se estudia su evolución. Se describe una posición de liderazgo desde el mismo nivel de los demás integrantes del grupo y no desde el tradicional esquema jerárquico. Describe los grupos de alto rendimiento y sus características. Describe también las de un equipo como un grupo de personas que trabajan con sinergia, se apoyan y complementan mutuamente obteniendo resultados superiores a la suma de los esfuerzos individuales. Sobre los equipos autodirigidos menciona que son producto de la evolución de los grupos, que demanda mucha capacitación y comunicación. Propone, cuando existen estructuras verticales rígidas, generar dos equipos, uno guía y otro de alto desempeño; el que toma el papel de guía establece la planeación estratégica y el otro desarrolla la operación. 
El tema central del libro El liderazgo..., se aborda en este segundo apartado y se define como: "La actitud que asumen los jefes para que sus colaboradores alcancen con entusiasmo los objetivos que le han sido encomendados", y más adelante afirma: "El líder es responsable de la vida y el destino de su gente" (p.69). Menciona antecedentes de liderazgo. Describe liderazgo situacional. Resume el modelo de Jersey y Blanchard; el de Rodríguez y García, y el de Reddin. Continúa describiendo exhaustivamente el modelo del líder trascendente. Propone un interesante ejercicio para presentarse a sí mismo y descubrir quién se es en realidad. El líder trascendente que se alimenta de tres elementos:

a) Trato personal enfocado al crecimiento de la persona. Las capacidades individuales que debe propiciar el líder: la concentración de valores, la orientación de propósitos, el crear el contexto de participación; cuyo proceso lo detalla estableciendo un marco de referencia, generando opciones necesarias, cambiando de estado, significando el trabajo y dignificando a la persona. Finalmente dar sentido a la colaboración individual en la empresa común.

b) El segundo elemento, desarrollado en la línea derecha del modelo se refiere a las responsabilidades y a las facilidades otorgadas a las personas para realizar su trabajo. Se capacita, faculta, participa, reconoce, responde y apoya.

c) El tercer elemento, a la izquierda del modelo, representa la dualidad obligaciónbeneficio de las características del líder y las organizaciones, como el poder, la calidad, la libertad, la confianza, el compromiso y la responsabilidad: "El líder cumple con la misión particular: hacer que sus colaboradores alcancen sus objetivos con entusiasmo y, además, con la misión específica de la organización" (p.89).

El capítulo sobre el poder, lo clasifica en coercitivo, de recompensa, de experto, de referencia y legítimo. De este último menciona que trae implícita la responsabilidad de ejercer los otros tipos de poder, no por gusto, sino por obligación. Clarifica que un líder que teniendo el poder no lo aplica se convierte en un evasor de su responsabilidad y el exceso en el uso del mismo lo convierte en un prepotente. Ambas situaciones llevan paradójicamente a perder el poder. Por tanto, el uso del poder debe hacerse en la medida y la circunstancia que se necesite.

Continúa el capítulo "Facultamiento o empowerment" que debería utiliza el término empoderamiento que es el que en referencia al término del inglés es aceptado por la RAE.

Este capítulo menciona según la definición de Wellins que "el facultamiento sucede cuando el poder pasa a los empleados, quienes experimentan el sentido de propiedad y control sobre sus trabajos" (p.100). Lo define como un proceso que requiere tiempo y donde intervienen varios factores tales como la capacidad de los empleados, la esencia y la estructura de la tarea, la cantidad de trabajo, la eficiencia de procesos y métodos, la tecnología y los recursos. Se analizan los 
aspectos relacionados con el respeto -que no puede enseñarse con capacitación—, la definición de responsabilidades, límites de autoridad —que se delega por respeto y para evitar conflictos-, estándares de calidad y otorgar reconocimiento al logro.

El tercer apartado trata sobre las organizaciones en sí. En cuanto a la estructura de las mismas, subraya la importancia de la flexibilidad y menciona que la mejor manera de trabajar es con una estructura base y puestos virtuales que permiten aparecer y desaparecer de acuerdo con el trabajo. El trabajo debe organizarse en productos, procesos y gente. La demanda y respuesta de la empresa a un bien o un servicio puede ser temporal por lo que las rígidas estructuras fijas, generan sobrecarga en los empleados en temporada alta o en la circunstancia inversa, están invariablemente desaprovechando recursos.

Establece y define las políticas organizacionales que son orientadoras de conducta. Menciona políticas que influyen en el ánimo de las personas y también la ineficacia de políticas generalizadas de reconocimiento, políticas que establecen normas de conducta y políticas que se practican temporalmente. Las políticas de desarrollo de personal suelen tener efectos motivacionales entre los mismos. Menciona finalmente las políticas de calidad que dan los lineamentos de lo que se espera de los empleados en términos de producción y servicio, desempeño y actitudes hacia los demás, dentro y fuera de la empresa. Las políticas son guías de comportamiento en el hacer y el actuar, tienen bases filosóficas, de valores y bases técnicas de diseño y pueden afectar la motivación de los empleados. Influye en el producto o servicio.

Estudia la cultura organizacional fundamentada en seis elementos: jefes, empleados, normas y políticas - como guía de actitud lenguaje de la empresa-, valores y principios de la misma y costumbres creadas por ella en términos de funcionalidad y fortaleza que aceptan y provocan cambios, que genera un clima de apoyo, contribución e interdependencia.

Termina el libro analizando el conflicto y el estrés como elementos que tienen facciones tanto positivas como negativas. Existen conflictos difíciles de enfrentar, los de tipo cognoscitivo que enfrentan a la persona con sus valores. Menciona métodos para solucionar los conflictos: el dominio, la dilación (que tiene el riesgo de acrecentarlo) y la negociación, orientándose ésta a la negociación por principios.

Finalmente se analiza el 'distres' como elemento negativo ocasionado tanto por saturación de actividad como por la falta de la misma y el estrés como sensación que genera el estado emocional adecuado para la solución de retos dentro de la organización. 